Goldschmidt 2021 Abstract

https://doi.org/10.7185/gold2021.5990

\section{Influence of trace As or Ni on pyrite precursors and nucleation kinetics at low temperature: high resolution mineralogical and crystallochemical analysis}

\author{
CAMILLE BAYA ${ }^{1}$, PIERRE LE PAPE ${ }^{1}$, BENOÎT \\ BAPTISTE $^{1}$, JESSICA BREST ${ }^{1}$, GAUTIER LANDROT ${ }^{2}$, \\ ERIK ELKAIM $^{2}$, VINCENT NOEL ${ }^{3}$, MARC BLANCHARD ${ }^{4}$, \\ GEORGES ONA-NGUEMA ${ }^{1}$, FARID JUILLOT ${ }^{5}$ AND \\ GUILLAUME MORIN ${ }^{1}$ \\ ${ }^{1}$ Institut de Minéralogie, de Physique des Matériaux et de \\ Cosmochimie (IMPMC), UMR 7590 Sorbonne Université- \\ CNRS-MNHN-IRD \\ ${ }^{2}$ Synchrotron SOLEIL \\ ${ }^{3}$ SLAC National Accelerator Laboratory \\ ${ }^{4}$ Géosciences Environnement Toulouse - CNRS - Univ Toulouse \\ III - IRD - CNES - OMP \\ ${ }^{5}$ ERL IRD 206, UMR 7590 CNRS-MNHN-Sorbonne Université
}

Presenting Author: camille.baya@sorbonne-universite.fr

Pyrite formation in sedimentary environments is a key step in the biogeochemical cycles of $\mathrm{Fe}$ and $\mathrm{S}$. Analyses of pyrite composition can be used as proxies to infer redox conditions prevailing in ancient sedimentary environments at the time of precipitation. However, the mechanisms of pyrite formation at low temperature are recurrently discussed because of its various potential mineralogical precursors involved at the molecular level. Parameters favouring or slowing pyrite nucleation have to be determined given this mineral's pivotal role in anoxic surface environments. While traces of certain elements such as As and $\mathrm{Ni}$ are widely observed in sedimentary pyrite, their influence on pyrite precipitation kinetics when present in solution prior to pyrite formation has been scarcely studied. Additionally, understanding the geochemistry of $\mathrm{As}$ and $\mathrm{Ni}$ during pyrite formation is crucial to predict the trapping and release of these potentially toxic trace elements in contaminated environments.

We will present recent results that show the influence of trace level As and $\mathrm{Ni}$ in pyrite nucleation kinetics at low temperature [1]. Pyrite syntheses were carried out at ambient temperature under conditions representative of early sediment diagenesis in the presence or absence of As or Ni. The mineralogy and the crystal-chemistry of the solids were monitored during pyrite formation at the molecular scale using X-ray diffraction, X-ray absorption spectroscopy at the $\mathrm{S}$ and $\mathrm{Fe} K$-edges, wide angle $\mathrm{X}$ Ray scattering coupled with pair distribution function and SEMEDXS microanalysis. We show that (1) the Fe-S mineralogical precursors of pyrite are identical in each scenario and correspond to a continuum of multi-sized FeS-type particles and (2) a delay or speed-up of pyrite formation is induced by the presence of traces of As or $\mathrm{Ni}$ in the initial solution, respectively. We suggest that their modes of incorporation to pyrite's precursors differ, explaining these antagonistic effects. These results imply that the presence of impurities of some trace elements could have a significant impact on pyrite formation in natural media and point to the need to consider the nature of these impurities when using pyrite composition to reconstruct paleo-redox conditions.

[1] Baya et al. (2021) Geochim. Cosmochim. Acta, in press. 